
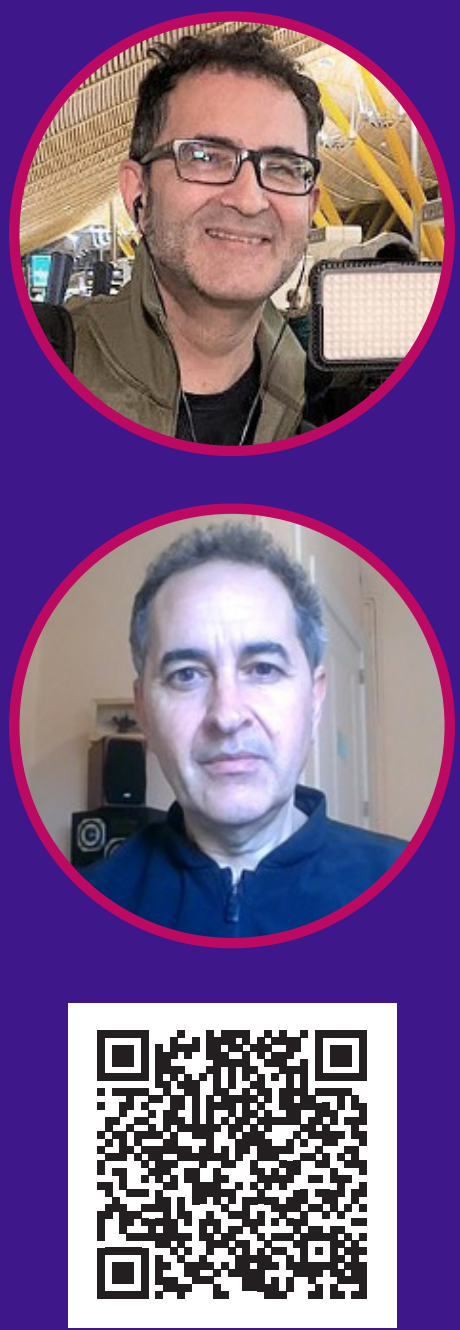

Videopresentación

\title{
Creatividad y Tecnología. Proyectos Audiovisuales en la Universidad y trabajo en grupo online durante el confinamiento por la COVID-19
}

\author{
Creativity and Technology. Audiovisual Projects at the University \\ and online group work during confinement by COVID-19
}

\author{
Dr. Vicente Sanz de León \\ Universidad Rey Juan Carlos, Madrid \\ vicente.sanz.deleon@urjc.es \\ Orcid: https://orcid.org/0000-0002-1784-41845849
}

Recibido: 17 de febrero de 2021.

Aceptado: 11 de marzo de 2021.

Publicado: 31 de mayo de 2021.

\author{
Dr. Gustavo Montes Rodríguez \\ Universidad Rey Juan Carlos, Madrid \\ gustavo.montes@urjc.es \\ Orcid: https://orcid.org/0000-0003-1811-0737
}

Received: February 17th, 2021.

Accepted: March 11th, 2021.

Published: May 31st, 2021.
(C) $(7) \ominus$ Esta obra está bajo una licencia internacional Creative
Commons Atribución-NoComercial-SinDerivadas 4.0.

DOI: https://doi.org/10.21555/rpc.vi1.2424

Cómo citar: Sanz de León, V., \& Montes Rodríguez, G. (2021). Creatividad y Tecnología. Proyectos Audiovisuales en la Universidad y trabajo en grupo online durante el confinamiento por la COVID-19. RPC, (1), 68-80. https://doi. org/10.21555/rpc.vi1.2424

Revista Panamericana de Comunicación, Año 3, N. 1, enero-julio 2021, pp. 68-80.

\section{RESUMEN}

Este artículo describe una estrategia docente innovadora llevada a cabo en el ámbito de la creación audiovisual a partir de la interrupción de las clases presenciales en la Universidad a causa de la pandemia del virus COVID-19. La Asignatura de Realización Audiovisual: Televisión, contempla en su guía docente un gran componente práctico evaluable, para cuya realización es imprescindible la infraestructura y medios de la Uni- 
versidad. A fin de garantizar su entrega y evaluación, interrumpida por el confinamiento, se diseñó un proyecto original, creativo y colaborativo que aprovecha las posibilidades que ofrecen las TIC. El proyecto parte de un guion elaborado colectivamente a través del juego del Cadáver Exquisito. El seguimiento, la elaboración de un cuestionario y los resultados de la creación, permiten concluir que el diseño de este proyecto ha contribuido a mejorar el manejo de las herramientas de edición, a desarrollar la creatividad de los alumnos, así como su implicación y motivación, además de haber implementado las dinámicas de trabajo en grupo a través de internet.

Palabras-clave: TIC, creatividad, realización audiovisual, trabajo en grupo, estudiantes universitarios, docencia.

\section{ABSTRACT}

This article describes an innovative teaching strategy carried out in the field of audiovisual creation after the interruption of face-to-face classes at the University due to the COVID-19 virus pandemic. The sub- ject of Audiovisual Production: Television includes in its teaching guide a large practical component that can be assessed, for which the University's infrastructure and resources are essential. To guarantee its delivery and evaluation, interrupted by the confinement, an original, creative and collaborative project was designed that takes advantage of the possibilities offered by ICT. The project is based on a script developed collectively through the Exquisite Corpse game. The follow-up, the elaboration of a questionnaire and the results of the creation, allow us to conclude that the design of this project has contributed to improve the handling of the editing tools, to develop the creativity of the students, as well as their involvement and motivation, in addition to having implemented the dynamics of group work through the internet.

Keywords: ICT, creativity, audiovisual production, group work, university students, teaching.

\section{INTRODUCCIÓN}

E I desencadenante de este proyecto surge a raíz de la suspensión de clases el 14 de marzo de 2020 a causa de la pandemia mundial provocada por el virus COVID-19. En la Asignatura de Realización Audiovisual: Televisión, del turno de tarde del cuarto curso del Doble Grado de Periodismo y Comunicación Audiovisual de la URJC, con 48 alumnos matriculados, quedó interrumpida la práctica final, en la que se debía realizar un programa de carácter innovador y creativo dentro del entorno televisivo mediante una planificación multicámara en el plató. En muchas ocasiones, este proyecto corresponde a la realización de un videoclip, ya que su concepción no exige las estructuras ni coherencias visuales exigibles en otros formatos. Se planteaba como un proyecto de contenido específico, con un carácter expresivo y formal alejado de una programación más generalista. Para garantizar su entrega se diseñó un proyecto que integrara el trabajo on line, la creación común y la originalidad.

En las asignaturas relativas a estas áreas, cualquier proyecto televisivo se concibe desde el principio como un trabajo en el que se utilizan los recursos e infraestructuras de la Universidad. Sin embargo, en el contexto COVID, el acceso a los equipos y los trabajos que 
implicaban reuniones físicas quedaban descartados por la posibilidad de contagio. Sin embargo, el espíritu de trabajo y creación colectiva no podía abandonarse, de manera que se diseñó un proyecto en torno a los parámetros originales; creación común, proyecto audiovisual y trabajo en grupo. Estos grupos debían mantener sus miembros tal y como se habían configurado antes del confinamiento.

\section{OBJETIVOS}

Este proyecto, basado en un proceso creativo como es el juego del Cadáver Exquisito, es una actividad de aprendizaje basado en proyectos que fomenta la creatividad y el trabajo en equipo. El uso de las TIC en la docencia universitaria facilita el aprendizaje a través de estrategias colaborativas que desarrollan la creatividad de los estudiantes más allá de las infraestructuras de la Universidad.

El objetivo es fomentar su creatividad y autonomía, así como garantizar la realización y entrega del proyecto mediante el uso de las TIC en todas las fases de su desarrollo: división de trabajo, guion, locución, realización y, especialmente, el montaje. Este proyecto poco convencional pone a prueba la motivación del grupo, sus capacidades e implicación, fomentando la discusión, la reunión y el intercambio de contenidos.

\section{METODOLOGÍA}

El diseño del proyecto tiene en cuenta las competencias establecidas en la guía docente, considerando la situación excepcional. Dos de estas capacidades generales se ponen a prueba: la capacidad para realizar la ordenación técnica de los materiales sonoros y visuales y la capacidad para aplicar procesos y técnicas implicadas en la organización y gestión de recursos técnicos en cualquiera de los soportes sonoros y visuales existentes. En cuanto a las capacidades específicas, el proyecto desarrolla muy concretamente la capacidad para definir temas de investigación, la habilidad para el uso adecuado de herramientas tecnológicas en las diferentes fases del proceso audiovisual, la capacidad de trabajo en equipo y de comunicación de las propias ideas, la creatividad y la capacidad de adaptación a los cambios. "Y está claro que si cambian los objetivos educativos y cambian las herramientas también deben cambiar las metodologías que se utilizan en los procesos de enseñanza y aprendizaje, pues hay nuevos objetivos [...] y hay nuevas herramientas [...]" (Marqués, 2013, p.16).

Se establece un punto de partida y un método de trabajo "virtualizando" las labores que se habrían llevado a cabo en la dinámica de la asignatura, pero manteniendo en todo caso las fases de trabajo, las funciones y puestos convencionales y utilizando una metodología ABP, es decir, de Aprendizaje Basado en Proyectos, esto es, "una metodología centrada en el aprendizaje, en la investigación y la reflexión por parte de los alumnos para llegar a una solución o una propuesta a un proyecto planteado inicialmente por el profesor." (López, 2018). De la misma forma, Prieto (citado en López, 2018) destaca los valores de esta metodología afirmando que "representa una estrategia eficaz y flexible que, a partir de lo que hacen los estudiantes, puede mejorar la calidad de su aprendizaje universitario en aspectos muy diversos." López (2018) señala también los inconvenientes del uso de esta metodología: "uno de sus aspectos más complejos de esta metodología es evaluar los proyectos, ya que se debe mostrar la adquisición de habilidades y destrezas." En nuestro caso, dicho inconveniente metodológico queda superado ya que dichas destrezas y habilidades quedan demostradas en los trabajos y refrendadas por sus comentarios.

Teniendo en cuenta lo anterior, el proyecto se realiza a través de una primera fase de construcción de guion, y una segunda de montaje de cada clip antes de su entrega. El análisis de un cuestionario elaborado al efecto y la evaluación concluyen el proceso.

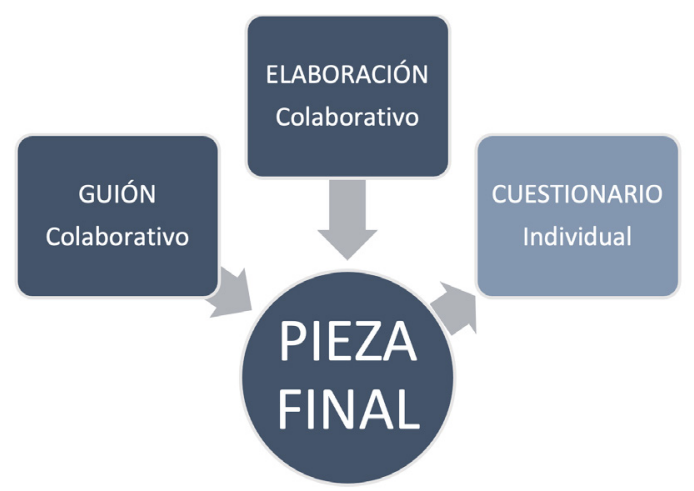

Gráfico 1. Proceso del proyecto. Fuente: Elaboración propia. 
El cuestionario, cuyo objetivo es obtener datos de primera mano acerca de la experiencia, se envía a todos los integrantes de los grupos y se pide su devolución tras su cumplimentación, recordando su voluntariedad. A través de la observación directa como procedimiento de obtención de datos (De Miguel, 2005. p. 279) se puede estudiar y realizar un seguimiento del proyecto, así como establecer un número de preguntas con sus correspondientes respuestas cerradas en el cuestionario, ya que según Cea D’Ancona (Cea, 1998) son fáciles de responder y codificar, reducen la ambigüedad de las respuestas, favorecen la comparabilidad y requieren menos esfuerzo por parte del encuestado (Cea, 1998). Esta metodología cuantitativa permite establecer unos porcentajes de respuestas que favorezcan el establecimiento de conclusiones.

\section{DESARROLLO DEL PROYECTO}

El punto de partida es el juego del Cadáver Exquisito. Este juego se basa en la inclusión del azar en el proceso creativo. Isidro Moreno (2002) describe el Cadáver Exquisito como un antecedente narrativo pretecnológico con aspiraciones de interactividad. La tecnología ha podido encontrar nuevos desarrollos y retos en el planteamiento de este juego, de manera que muchas ideas y anhelos artísticos se han podido ver cumplidos y ampliados con la incorporación de las nuevas tecnologías al uso cotidiano en la sociedad. Desde los años 90 surgen sitios en los que se proponen y fomentan este tipo de creaciones. Uno de los referentes es Sito, que, desde 1993, aloja proyectos de arte colaborativos basados en Internet (Sito, https://www.sito.org/).

La llamada Web 2.0 trae consigo una implementación de aplicaciones y herramientas que internet que influye y acelera este proceso. Posibilita que los miles de usuarios contribuyan a proyectos comunes y hagan de la red una fuente inagotable de nuevos contenidos. Referidas a vídeos colaborativos que han utilizado la potente herramienta de internet para compartir y armar una pieza audiovisual han sido, por ejemplo, Life in a day, producido por el director Ridley Scott, así como la versión en España de la directora Isabel Coixet, Spain in day, que, a través de miles de vídeos recibidos, elabo- ra un documental sobre la vida y cotidianeidad de los españoles en ese año (RTVE. 2016). En el año 2000 el director tailandés Apichatpong Weerasethakul presenta una producción titulada Mysterious Object at Noon, en la que un sorprendente comienzo "será el movimiento desencadenante de un fascinante cadáver exquisito, un relato de construcción colectiva que la cámara documental del cineasta [...] irá armando a partir de diversas voces y estrategias." (Costa, 2016).

La decisión de obtener un guion a través de este sistema surge precisamente por la idea de incluir un proyecto experimental que añada creatividad literaria con un componente de aleatoriedad, con un guion que no siga unas normas básicas y donde no exista una estructura clara ni un conflicto específico que identifique lugares o tiempo. Este punto de partida es útil para añadir en el montaje una serie de imágenes a modo de contraste o de refuerzo visual, cuyo valor creativo se encuentra precisamente en esa combinación. Este formato facilita la extensión de dicha inclusión de contenidos no sólo a la imagen fija y a la imagen en movimiento, sino también a las posibilidades creativas del grafismo, la música o la animación. Siguiendo la teoría de Roland Barthes (1990), el relato se sustenta gracias a varias sustancias expresivas, entre otras, el lenguaje articulado, oral o escrito y la imagen, fija o móvil.

Por otro lado, es imprescindible en las primeras fases de cualquier proyecto, especialmente en el entorno audiovisual, explorar su viabilidad. Tras fijar la idea de partida, es en la fase de Toma de contacto y Documentación, donde se decide "la viabilidad y el grado de dificultad" (Barroso, 1996, p. 507). Esta fase certificó que el proyecto era perfectamente viable, ya que la disponibilidad y destreza en el uso de dispositivos y herramientas on line de los participantes garantizan su puesta en marcha. La formación y uso de dichas tecnologías a lo largo de etapas académicas anteriores han permitido que los alumnos estén familiarizados con su uso y las conozcan en gran medida. Según Manuel Area (2010, p.3) "la alfabetización de los individuos ante los múltiples lenguajes y códigos (textuales, icónicos, hipertextuales, audiovisuales, multimedia...) que adopta la información debería ser una meta recurrente y permanente de todo el sistema educativo desde la educación 
infantil hasta la superior." La puesta en marcha del proyecto se realiza en tres fases:

\subsection{Propuesta y viabilidad}

Los grupos se conforman por la unión de otros grupos más pequeños, de 8 integrantes, que habían trabajado antes de la suspensión de las clases presenciales, por lo que están compuestos finalmente por 3 grupos de 16 miembros. Antes de comenzar, ya que el sistema de trabajo y las herramientas con las que se contaban no estarían disponibles, se procedió a una consulta a través de la delegada de grupo acerca de la viabilidad del proyecto.

A través de una consulta de este tipo, se trata de confirmar que todo el mundo puede trabajar en remoto y tiene la posibilidad de grabar, aunque sea con el móvil. Actualmente, la mayoría del alumnado crea un grupo en alguna aplicación móvil para compartir información sobre el curso o sobre alguna asignatura concreta. En este caso, el 100\% de los alumnos consultados afirmaron que utilizaron whatsapp como herramienta de comunicación con el grupo.

Desde la Universidad está a disposición del alumnado la plataforma on line MyApps, donde se puede acceder en remoto a los programas de edición necesarios. En el desarrollo de la propuesta se insiste en todo momento en que, dado que no hay posibilidad de grabar en circunstancias normales por las limitaciones espaciales y técnicas, hay que adaptarse a posibilidades asequibles y viables. Por lo tanto, el proyecto se adapta a los sistemas recurrentes que se han desarrollado y aumentado en estas circunstancias a la hora de intercambiar y crear contenido: el uso imágenes del dispositivo móvil para su captación y envío. El conjunto del profesorado en España, según Vázquez-Cano (citado en Figueras-Maz et alt., 2018) valora positivamente estos dispositivos, sobre todo desde una perspectiva didáctica, cuando se utilizan "para realizar videoconferencias, para gestionar de forma ubicua chats y foros académicos relacionados con las asignaturas o para el fomento de la participación del alumnado en la vida académica e investigadora. Asimismo, la creación y visualización de vídeos" (p.162). De esta forma se puede intercambiar material, aunque no se disponga de equipo de grabación, con todos los miembros del grupo.

La respuesta de los alumnos certifica que la idea tiene buena acogida. Teniendo en cuenta las limitaciones del confinamiento, se aclara que es difícil obtener imágenes que contemplen muchos y variados entornos. Se sugiere que, si es posible, las imágenes sean originales, pero también se especifica que si en algún momento se considera que una imagen es fundamental para conseguir el efecto esperado y no se dispone de ella, se pueden incluir documentos de archivo en el montaje. El Grupo 2 (G2 en adelante) consultó la posibilidad de usar íntegramente imagen de archivo y basó su trabajo en una selección de imágenes de obras preexistentes, creando un collage de géneros y estilos unidos por el texto. Comprobada la viabilidad, se planteó directamente el trabajo, sus características, fases y fechas de entrega.

\subsection{Desarrollo de los proyectos, entrega de guion y montaje final}

El proyecto propone la utilización de las posibilidades que ofrece el teléfono móvil para sortear las dificultades que imponen las circunstancias COVID. Hace unos años se puso en marcha el primer proyecto de Crowdshooting (Sanz, 2016), que proponía la grabación de un videoclip con aproximadamente 20 tiros de cámara que operaban los distintos participantes que también formaban parte como extras del videoclip. En el presente proyecto se trata también de constatar cómo el uso de la telefonía móvil puede generar imágenes perfectamente válidas para una creación colectiva. Por ello, y dado que ya se ha trabajado el género informativo y documental en varias asignaturas, se propone realizar una pieza más abierta y creativa, experimental y participativa, que se alejase de lo real, ya que el estado de alarma impide salir a grabar fuera del entorno doméstico.

El proyecto consta de dos fases. La primera configura el guion como base de la pieza y la segunda resulta de la pieza montada en función del guion. La primera fase parte del juego de palabras inventado por los surrealistas Cadavre Exquis (Cadáver Exquisito). Se ex- 
plica en qué consiste el juego y que el objetivo es crear una obra de forma colectiva, a partir de una primera propuesta por parte de un participante y continuando después la creación varios autores. Acorde al proyecto, se adapta la primera fase a esta forma de crear textos o poemas mediante la sugerencia aleatoria de palabras por parte de un grupo, tal y como se expone a continuación:

1. Cada miembro del grupo (compuesto por 16 participantes) tiene que proponer cuatro palabras: 1 sustantivo, 1 verbo, 1 adjetivo o adverbio de modo y 1 complemento circunstancial de lugar o adverbio de lugar. Una vez escritos, se reúne cada tipo de palabra en un mismo grupo. Habría un conjunto de 16 sustantivos, 16 verbos, 16 adjetivos 0 adverbios de modo y 16 complementos circunstanciales de lugar o adverbios de lugar. Después, de manera aleatoria se van extrayendo de cada grupo 1 sustantivo, 1 verbo, 1 adjetivo 0 adverbio de modo y 1 complemento circunstancial de lugar o adverbio de lugar. Con esas cuatro palabras debe formarse una frase pudiendo añadir alguna palabra más, como artículos, preposiciones o conjunciones que ayuden a cerrar y dar sentido al texto. Resultan 4 frases.

2. Para comprender mejor el sistema se ilustra este ejemplo con 4 propuestas, unidas por el azar:

$\begin{array}{llll}\text { Cielo } & \text { Caminar } & \text { Verde } & \text { Playa } \\ \text { Cuchillo } & \text { Comer } & \text { Ancho } & \text { Alcoba } \\ \text { Buitre } & \text { Colorear } & \text { Sofisticado } & \text { Montaña } \\ \text { Carta } & \text { Asentir } & \text { Amargado } & \text { Ruina }\end{array}$

Si se extrae una palabra al azar de cada columna y se forman frases, se obtienen textos como:

"El amargado buitre come en su alcoba. Asiente el cielo en la verde montaña y camina el ancho cuchillo por su ruina. Tu carta sofisticada colorea esta playa”.
Al ser 16 propuestas, resulta un texto de unos 8 párrafos que sería la base del montaje y condicionaría su duración (el grupo puede elegir un texto poético o una prosa sencilla). El texto pasa por los diferentes componentes de los grupos de edición, montando por párrafos con las imágenes grabadas por los participantes y se completa la pieza con una música elegida por los coordinadores. Las imágenes que acompañan al texto no deben ser una reiteración de lo que ya expone el texto. Esta decisión corre a cargo de cada montador o grupo de montadores. Se sugiere que el texto sea locutado.

3. Para organizar el trabajo es necesario la configuración de diferentes equipos. Estas funciones son, en principio, una sugerencia para estructurar el trabajo, si bien el grupo decide y asigna roles en función de sus necesidades. Los equipos asumen la responsabilidad de:

a. Realización. Uno o dos coordinadores que organicen y marquen tiempos (como ya ha habido realizadores y guionistas se podría rotar el puesto).

b. Guion y Redacción. Configurar y redactar el texto definitivo. Sorteando también los grupos de palabras que configuran las frases.

c. Documentación. Reunir y enviar imágenes de todos los participantes para el montaje

d. Música

e. Grafismo.

f. Edición parcial por bloques

g. Edición final

Tras la descripción y las especificaciones pertinentes, el trabajo se pone en marcha y se entregan los primeros resultados de la primera fase que, recordemos, consiste en la elaboración de un texto como base para 
el montaje. Cada grupo redacta un texto basado en las siguientes palabras:

\begin{tabular}{|l|l|l|l|}
\hline Sustantivos: & Adjetivos & Verbos & Adverbio de lugar \\
\hline Sustantivo & Exuberante & Embalsamar & Alrededor \\
\hline Luna & Brillante & Alcanzar & Cercano \\
\hline Silla & Maravilloso & Fumar & Alli \\
\hline Diamante & Precario & Empobrecer & En el mar de Conil \\
\hline Patines & Rápido & Bailar & En Madrid \\
\hline Ventana & Azul & Mirar & Delante \\
\hline Lupa & Borroso & Sentir & En la acera \\
\hline Cama & Feo & Correr & Fuera \\
\hline Perro & Radiactivo & Padecer & En la habitación \\
\hline Luz & Honesto & Escuchar & En la calle \\
\hline Lámpara & Fugaz & Dormir & En casa \\
\hline Atardecer & Cálido & Amar & Aquí \\
\hline
\end{tabular}

Figura 1. Conjunto original de palabras del agrupadas en columnas titulado Deleite Confinado. Fuente: Grupo 1

\begin{tabular}{|c|c|c|c|}
\hline VERBOS & ADBERVIOS & SUSTANTIVOS & ADJETIVOS \\
\hline viajar & pronto & odio & senil \\
\hline consumir & apenas & biberón & sexual \\
\hline ser & caóticamente & explosión & hipnotizante \\
\hline bajar & también & madre & emergente \\
\hline morir & jamás & hogar & abominable \\
\hline vivir & lamentablemente & fantasía & idealizado \\
\hline cruzar & pacientemente & alma & intenso \\
\hline conseguir & fuertemente & profeta & cutre \\
\hline rajar & fugazmente & entusiasmo & ensordecedor \\
\hline avivar & seguramente & color & peligroso \\
\hline lamer & entonces & integridad & cruel \\
\hline sostener & ahí & muerte & ligero \\
\hline iluminar & aleatoriamente & libertad & soberbio \\
\hline fallar & aquí & interés & público \\
\hline sobrevivir & todavía & naturaleza & aburrido \\
\hline
\end{tabular}

Figura 2. Conjunto original de palabras del agrupadas en columnas titulado Biberones, tetas y profetas. Fuente: Grupo 2.

\begin{tabular}{|l|l|l|l|}
\hline \multicolumn{1}{|c|}{ Sustantivo } & \multicolumn{1}{|c|}{ Verbo } & Adjetivo/Adverbio & $\begin{array}{l}\text { Complemento C. } \\
\text { Lugar }\end{array}$ \\
\hline Cama & Comer & Bonito & Playa \\
\hline Papel & Mirar & Maligno & Montaña \\
\hline Lágrima & Extrañar & Alegre & Jardin \\
\hline Mascarilla & Recordar & Solidario & Casa \\
\hline Universo & Añorar & Artística & Buhardilla \\
\hline Ventana & Andar & Aburrido & Parque \\
\hline Boligrafo & Abrazar & Nostálgico & Comedor \\
\hline Teléfono & Bailar & Rápido & Salón \\
\hline Sofá & Correr & Generoso & Cocina \\
\hline Fuego & Caer & Eterno & Suelo \\
\hline Libertad & Reflexionar & Efimero & Cielo \\
\hline Libro & Disfrutar & Caluroso & Terraza \\
\hline Móvil & Olvidar & Misterioso & Calle \\
\hline Cielo & Dormir & Brillante & Escaleras \\
\hline Revista & Tumbarse & Suave & Habitación \\
\hline Ventana & Leer & Tranquilo & Salón \\
\hline
\end{tabular}

Figura 3. Conjunto original de palabras del agrupadas en columnas titulado La Ventana de mi habitación. Fuente: Grupo 3.

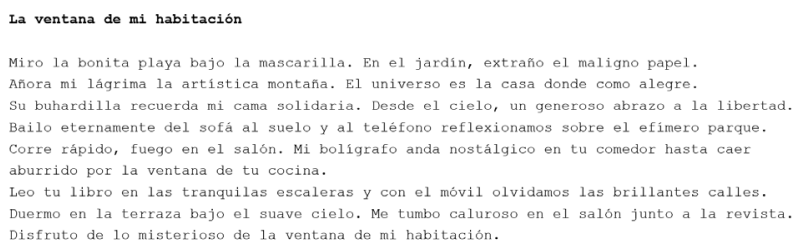

Figura 4. Guion final de La Ventana de mi habitación. Fuente: Grupo 3.

Esta primera fase concluye con la elaboración de los textos que servirían como base para el montaje de las piezas audiovisuales. El género literario elegido por el G2 fue la prosa y la poesía, el género elegido por el G1 y G3. El siguiente paso consiste en el montaje de la pieza.

\section{RESULTADOS}

Por parte del profesorado, el seguimiento de los trabajos consistió en la supervisión de cada parte del proyecto y su entrega, sí como la recomendación y resolución de dudas en cada una de las fases. Los tra- 
bajos se entregaron en los términos especificados y se evaluaron sobre 10. La pieza La ventana de mi habitación del G1 (Sancho y Moral, 2020), dura 01:24'. Incluye en la pieza imágenes originales y música de archivo. Es el trabajo que mejor se corresponde con el planteamiento inicial. Su calificación destaca con un 9 valorando especialmente la inclusión de imágenes totalmente originales, la buena selección de la música in crescendo y una locución narrada con el tono de emoción idóneo. De cara a mejorar el resultado, se deberían haber incluido más imágenes que mejoraran el ritmo del montaje.
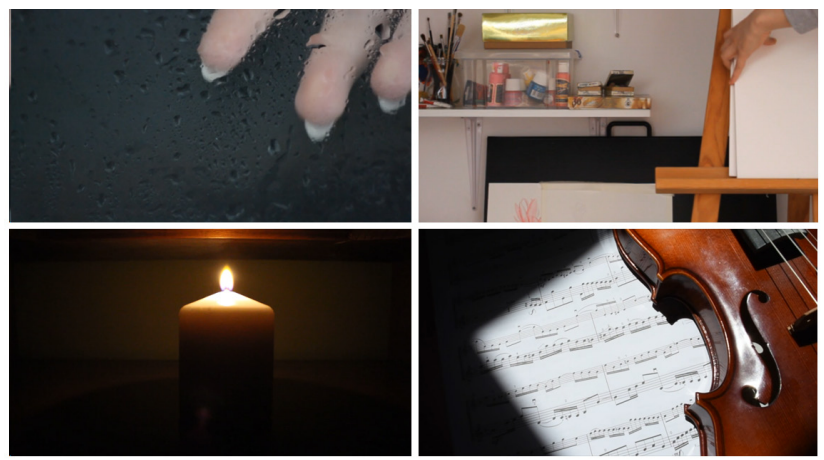

Figura 5. Captura de fotogramas de La Ventana de mi habitación. Fuente: Grupo 3.

Biberones, tetas y profetas, del G2 (Brandariz y Balán, 2020), dura 03:52'. Su calificación es de 8,8. Esta calificación supone un reconocimiento a la labor de documentación y a la búsqueda de imágenes de archivo para el montaje, si bien los diferentes formatos son muy diferentes y no resulta una edición muy equilibrada por dicha diferencia en la calidad y compresión de las imágenes. Otro gran valor es la música original compuesta exclusivamente para la pieza.
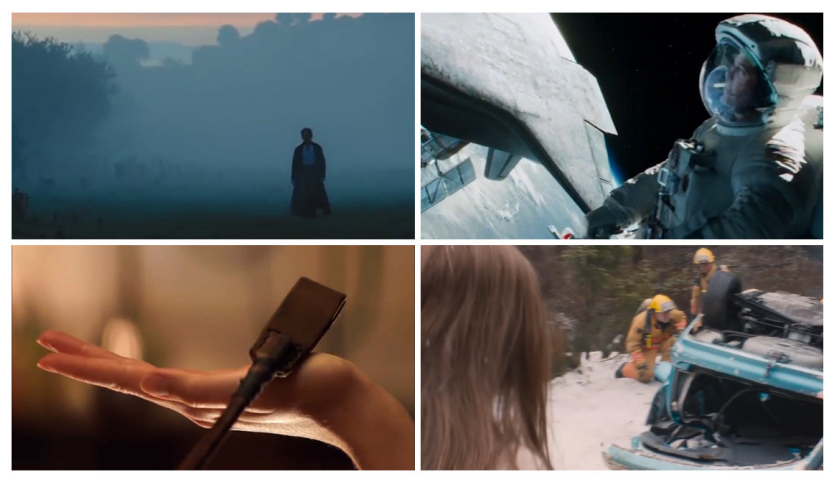

Figura 6. Captura de fotogramas de Biberones, tetas y profetas. Fuente: Grupo 2.
Deleite Confinado del G3 (Fernández-Pacheco, 2020), dura 00:52'. Su calificación es de 8,5. Su montaje incluye una buena combinación de imágenes de archivo y originales y una correcta locución. La música de archivo se integra perfectamente creando un buen ritmo en el montaje. El distinto origen y calidad de las imágenes provoca que no haya una unidad visual en el resultado final.

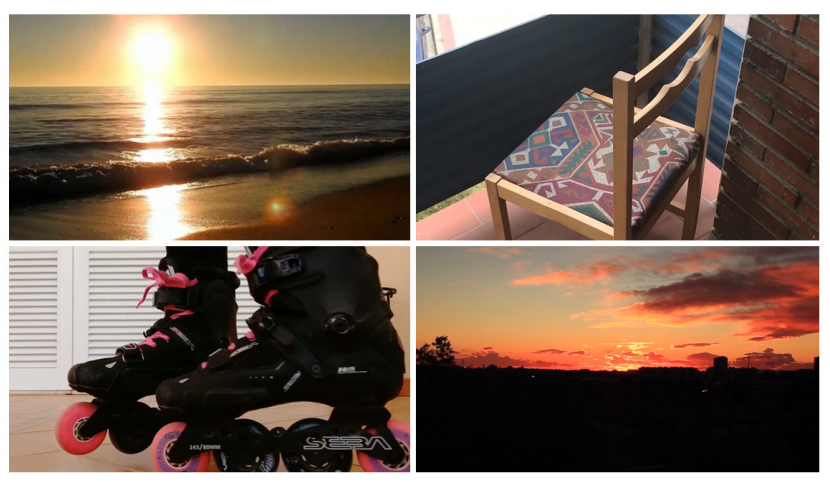

Figura 7. Captura de fotogramas de Deleite Confinado. Fuente: Grupo 1.

Una vez entregados y evaluados los trabajos, se procede a una consulta mediante un cuestionario orientado a recabar información de primera mano. Vinculándolo con lo anterior, permite establecer conclusiones a partir de la opinión de los alumnos acerca de la experiencia. Por otro lado, el cuestionario se convierte también en un instrumento para detectar carencias de cara a proyectos futuros. El cuestionario cuenta con diez cuestiones en total. Ocho afirmaciones para valorar de 1 a 5 algunos aspectos del trabajo, suponiendo la opción 5 estar muy de acuerdo y la opción 1 estar muy poco de acuerdo. La pregunta 9 hace referencia a las herramientas de comunicación e intercambio de archivos que se han utilizado y la diez, expone una serie de géneros a los que los participantes deben asociar la pieza entregada. Finaliza con unas líneas optativas invitando a dejar las observaciones o comentarios particulares que se consideren oportunos. Las cuestiones planteadas son las siguientes:

1. Recomendaría proyectos de este tipo para experimentar con la imagen y el sonido. 
2. Ya he hecho anteriormente en la Universidad un trabajo de estas características.

3. El uso de las TIC ha sido fundamental para este trabajo.

4. Sin Internet habría sido imposible la realización del trabajo en los términos planteados

5. Plantearía o participaría a nivel profesional o artístico en la realización de una obra similar.

6. La creatividad ha sido determinante para la realización del trabajo.

7. He aprendido o incrementado mi conocimiento de herramientas de edición audiovisual. (Edición, descarga, intercambio de archivos...)

8. Estoy satisfecho con el resultado del trabajo realizado.

9. ¿Qué herramientas de comunicación has utilizado más para comunicarte con el equipo? WHATSAPP, DRIVE, EMAIL, OTRAS (Escribirlas)

10. Señala en qué clasificación englobarías el trabajo realizado. INFORMATIVO, DOCUMENTAL, VIDEOARTE, EXPERIMENTAL, FICCIÓN

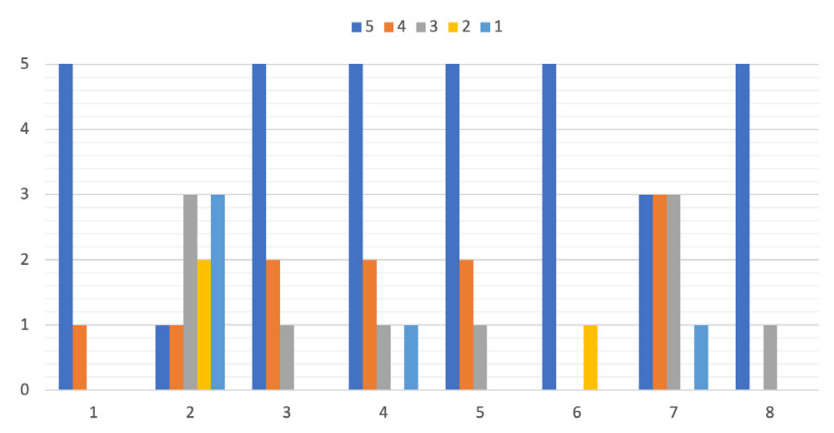

Gráfico 2. Resultados del cuestionario valorando de 1 a 5 las opciones. Fuente: Elaboración propia.
Las respuestas a la segunda cuestión muestran que un alto porcentaje de los alumnos no se han encontrado con proyectos de estas características a la vez que el 90\% de los encuestados marca la opción 5 en la primera cuestión, recomendando este tipo de experiencias para experimentar con la imagen y el sonido. Esto confirma el alto grado de aceptación del proyecto y la eventual inclusión de su metodología en otras asignaturas de cara a fomentar la colaboración en la construcción de contenidos experimentales en el entorno audiovisual. La tercera cuestión aborda la importancia de las TIC en una creación de estas características y cuenta con un muy favorable acuerdo del $70 \%$, señalando la opción 5 , que advierte de la necesidad de las TIC para poder realizar dichos proyectos. En la cuarta cuestión, marcan la opción 5 un 60\% de los encuestados, manifestando su alto grado de acuerdo en que sin conexión a internet no sería posible su realización en los términos planteados. El ejercicio está planteado para una rápida y ágil comunicación, intercambio de archivos, calendario y plazos de trabajo que sin duda haría imposible su cumplimiento sin una conexión a la red. Sólo un $10 \%$ manifiesta su total desacuerdo. Se entiende que el proyecto se puede llevar a cabo sin conexión, pero los tiempos y procesos se podrían alargar tanto que prácticamente lo harían inviable. En la quinta cuestión, un $70 \%$ está muy de acuerdo en participar profesional o artísticamente en un proyecto de este tipo, marcando la opción 5 y confirmando nuevamente su alta aceptación de la propuesta. Uno de los desafíos de dicha propuesta, consiste en fomentar la creatividad de los participantes. En la sexta cuestión, un 90\% marca la opción 5, confirmando con sus respuestas estar muy de acuerdo en que la creatividad es determinante para la realización de las piezas. La séptima cuestión plantea si se ha aprendido o incrementado el conocimiento de herramientas de edición audiovisual, tales como edición, descarga, intercambio de archivos, etc. Un 30\% marca un 5, un 30\% un 4 y otro $30 \%$ un 3, mientras que un $10 \%$ un 1 . Este pequeño porcentaje de desacuerdo es comprensible ya que, en muchos casos, dichas herramientas se conocen por circunstancias particulares o profesionales, o bien por el hecho de que al llegar a cuarto curso ya se han manejado muchas herramientas de edición. Pero el alto 
grado de acuerdo en manifestar que realmente sí han aprendido, supone un dato muy positivo desde el punto de vista docente, como constata la octava afirmación. Un 90\% marca la opción 5 al referirse al grado de satisfacción con el resultado final, evidenciando, junto con las anteriores consideraciones, el grado de idoneidad y pertinencia del proyecto.

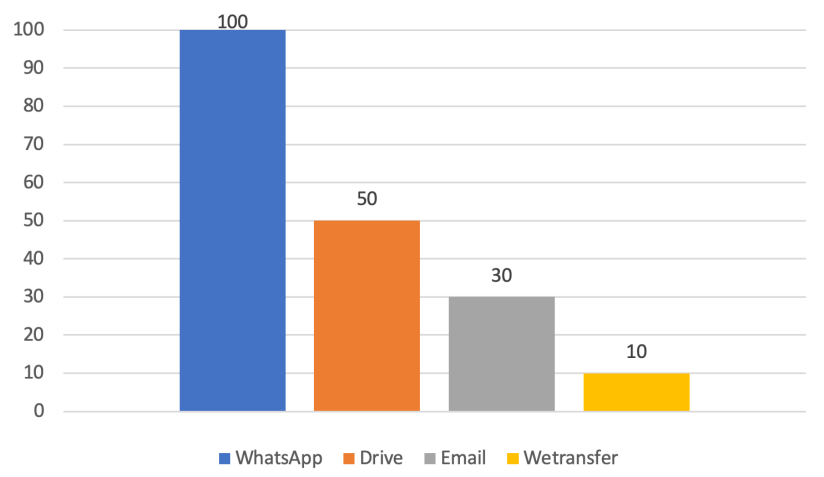

Gráfico 3. Herramientas de Comunicación e intercambio de archivos más utilizadas según la pregunta 9 del cuestionario. Fuente: Elaboración propia.

La pregunta 9 trata de confirmar el uso de muchas herramientas paradigmáticas de las TIC y de especificar algunas de ellas. Se puede afirmar que la herramienta más eficaz de comunicación, por su inmediatez, coste y amplia implantación, ha sido WhatsApp, ya que el $100 \%$ de los encuestados manifiesta haberla usado, seguida por la herramienta de intercambio de archivos y trabajo on line Drive, que con un 50\% permite confirmar que la mitad de ellos han recurrido a ella. El correo electrónico lo han usado en un porcentaje de un 30\% y el $10 \%$ ha utilizado Wetransfer para el intercambio de archivos de grandes dimensiones, ya que permite en su versión gratuita el envío de archivos de hasta un máximo de $2 \mathrm{~Gb}$. Esto confirma el uso por parte de los alumnos de dichas herramientas, posibilitando la comunicación y envío de archivos de gran tamaño a través de las plataformas gratuitas de internet.

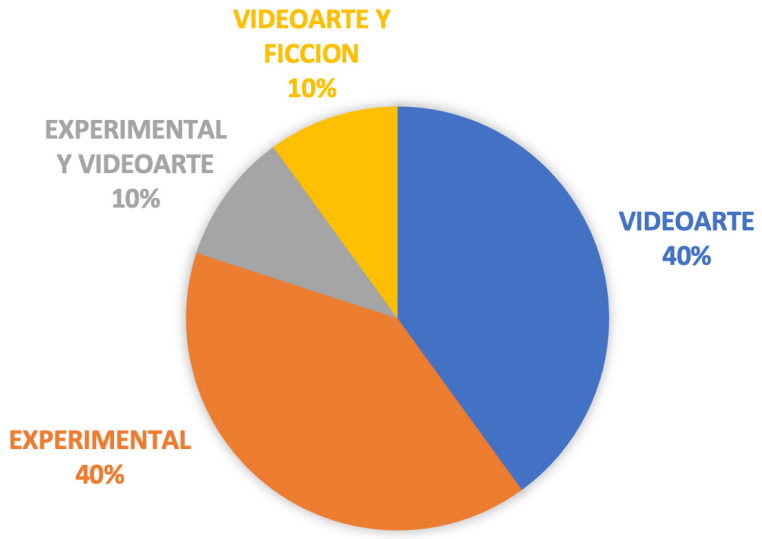

Gráfico 4. Clasificación del proyecto según la pregunta 10. Fuente: Elaboración propia.

Un $40 \%$ de los encuestados considera que el proyecto es puramente experimental. El mismo porcentaje piensa que es exclusivamente videoarte. Un 10\% los ha considerado conjuntamente como videoarte y experimental y un mismo porcentaje videoarte y ficción. Estas opciones revelan la opinión de los encuestados asociando el proyecto a unas categorías poco frecuentes en los contenidos televisivos generalistas. De esta forma asumen el desafío de incorporar su propio lenguaje y estructura en su creación.

Los comentarios de los alumnos arrojan una información determinante a la hora de establecer conclusiones sobre el proyecto planteado. Todos los comentarios personales enviados coinciden en su positiva valoración de la experiencia.

Los alumnos del Grupo 1 que incluyeron comentarios personales manifestaron:

"Desde mi punto de vista, creo que el último trabajo realizado ha sido una opción muy acertada porque nos ha permitido plasmar nuestra creatividad audiovisual de una manera que no habíamos realizado durante la carrera. Además, nos ha mostrado la capacidad de trabajo en equipo que podemos tener, incluso sin comentar los asuntos referentes al trabajo de forma física" (G1). 
"Me ha gustado mucho que se nos haya dado la oportunidad de crear libremente, aunque dentro de unas directrices por supuesto. La idea del proyecto ha sido genial y entretenida de hacer, probablemente la organización entre el grupo y la creatividad individual sean lo más importante para un trabajo así. A lo mejor incluso se podría hacer una especie de concurso en clase con este proyecto, esto podría llamar más a la creatividad y esfuerzo de los alumnos y conseguir resultados increíbles" (G1).

"Ya hemos hecho algunos proyectos de ficción en grupo, pero al tener que realizar un texto a partir de palabras aleatorias ha abierto un abanico de posibilidades y da pie a mayor creatividad. Creo que es una buena forma de poner en práctica todos los recursos que hemos aprendido en cuanto a realización y es divertido porque cada uno se imagina algo distinto, aunque el resultado es común" (G1).

Los alumnos del Grupo 2 que incluyeron comentarios personales manifestaron:

"Es poco usual encontrar profesores dispuestos a plantear actividades creativas en la que los alumnos podamos fomentar la imaginación, la creación, el pensamiento crítico, y el trabajo en equipo (en el que seamos nosotros mismos quienes nos organicemos y lideremos), por ello esta actividad fue acogida con mucha ilusión y ganas por parte de toda la clase. La predisposición de todos fue ejemplar y yo, personalmente, no he visto esta predisposición generalizada en la clase muchas veces en lo que llevamos de carrera. Gracias por sacar esto de nosotros y darnos la oportunidad de crear con libertad" (G2).

"La asignatura ha sido de las más innovadoras y estimulantes de la carrera. Creo que esta es la mejor forma de trabajar en equipo, dejando bastante libertad a la hora de realizar el trabajo, y existiendo diálogo entre profesor y alumnado. Gracias por confiar en nosotros Vicente, ha sido un placer y hemos disfrutado mucho realizándolo" (G2).

"El trabajo ha sido muy satisfactorio, es una muy buena alternativa en esta situación tan atípica. Con este trabajo hemos fomentado el trabajo en grupo, la comunicación entre compañeros y la creatividad" (G2).

\section{Del Grupo 3 se incluyó un solo comentario:}

"Esta actividad ha sido muy creativa. En un principio lo veíamos como algo más difícil de hacer, sobre todo por no poder tener la facilidad de poder grabar en cualquier lado. Pero poco a poco fuimos viendo que era muy asequible y que era muy entretenida de hacer. Además, es una actividad bonita y creativa, cuyo resultado es verdaderamente bueno, es muy agradable de hacer y ver. Recomiendo con creces hacer este tipo de actividades no sólo por su resultado, sino para aprender a transmitir con imágenes las palabras y para aprender a editar, no siempre desde la rigurosidad de noticias o medios más formales" (G3).

\section{CONCLUSIONES}

Este proyecto ha cumplido con los objetivos planteados desde el momento en el que se dan por entregados los trabajos audiovisuales terminados, suponiendo a la vez el cierre de un curso que pudo continuar con la práctica pese a la situación de emergencia vivida, gracias a la determinación del profesorado y del alumnado. Su estudio concluye y revela aspectos importantes a tener en cuenta en la enseñanza universitaria. 
1. La elaboración de un cuestionario para evaluar la experiencia de los alumnos respecto a su trabajo creativo se ha mostrado como una herramienta eficaz para comprobar cómo los alumnos han seguido los procedimientos adecuados y utilizado los recursos idóneos para elaborar sus proyectos audiovisuales, evidenciando que han ampliado sus conocimientos a la hora de trasladar conceptos teóricos a la práctica profesional. De la misma forma, permite al docente hacer un seguimiento exhaustivo del proceso de aprendizaje de los alumnos, detectando eventuales carencias y la posibilidad de realizar modificaciones de planteamiento para mejorar la experiencia docente.

2. Las TIC no solo permiten sustituir determinadas herramientas de comunicación y creación audiovisual, sino que pueden ser en sí mismos instrumentos y herramientas de creación propios, ampliando las posibilidades y creando nuevos flujos y nuevas dinámicas de trabajo, convirtiéndose hoy día en fundamentales para el proceso creativo audiovisual. La dificultad de no trabajar y no tener una Comunicación inmediata como en el aula, se suple con las plataformas actuales de Comunicación a través del teléfono móvil.

3. El factor creativo, alejado de un planteamiento convencional a la hora de crear contenidos, fomenta la experimentación y la práctica con las herramientas de edición audiovisual, contribuyendo así a un mayor conocimiento de sus posibilidades, de la misma forma que invita a participar y resulta un aliciente extra en los proyectos.

4. Dadas las características del proyecto, los alumnos se vieron obligados a superar las dificultades inherentes a la ausencia de referencias genéricas y de formatos, investigando y descubriendo estructuras narrativas inéditas que sustentasen un proceso de trabajo también no- vedoso. Por tanto, los productos audiovisuales elaborados se alejan de las formas de representación convencionales y se caracterizan por su originalidad y la utilización libérrima de la imaginación creativa.

5. La experimentación con la narrativa y el lenguaje audiovisual crea contenidos con un mensaje y significado propios.

6. Plantear un proyecto de estas características se ha revelado como una opción idónea para poder realizar una práctica audiovisual que reúna su carácter original, colaborativo, audiovisual, y on line.

7. La evaluación de los proyectos y la propia opinión manifestada de los alumnos, refrenda y confirma la pertinencia, idoneidad y satisfacción con el proyecto.

8. Los trabajos universitarios colaborativos on line pueden complementar la docencia presencial o incluso ser una disciplina en sí mismos, ya que el proceso que tradicionalmente se ha seguido en la creación audiovisual se ha podido "virtualizar" y ser fiel sus procedimientos y sus resultados. \} 


\section{REFERENCIAS}

» Area, M. (2010). "¿Por qué formar en competencias informacionales y digitales en la educación superior?" RUSC. Revista de Universidad y Sociedad del Conocimiento, 7(2), 3. Disponible en https://bit.ly/2ROBd55

» Barthes, R. (1990). La aventura semiológica. Barcelona, España. Paidós.

» Barroso, J. (1996). Realización de los Géneros Televisivos. Madrid, España. Comunicación Audiovisual.

» Cea D’Ancona, M. A. (1998). Metodología Cuantitativa. Estrategias y técnicas de investigación social. Madrid, España. Síntesis Sociología.

» Costa, J. (28 de abril de 2016). La utopía fabulada. El país. https:// elpais.com/cultura/2016/04/28/actualidad/1461844696_058302. html

» De Miguel, R. (2005). "La observación sistemática y participante como herramienta de análisis de los fenómenos comunicativos". En Berganza, M. A y Ruiz, J. A. Investigar en comunicación. (p. 279) Madrid, España: Mc Graw Hill.

» Figueras-Maz, M., Ferrés, J. y Mateus, J.C. (2018). "Percepción de los/as coordinadores/as de la innovación docente en las universidades españolas sobre el uso de dispositivos móviles en el aula". Revista Prisma Social, (20), 162. Disponible en https://bit. ly/2psvnGw

» Sancho, E., y Moral, E., (2020). La ventana de mi habitación. https://drive.google.com/file/d/1RG1y9m6FFu406qMBCoEKQVUPSNQ-xLYx/view? usp=sharing

» Brandariz, A., y Balán, A., (2020). Biberones, tetas y profetas. https://drive.google.com/file/d/127LpQTJcaYlf37vb6s2t2VwqVyXxETky/view?usp=sharing

» Fernández-Pacheco, T, (2020). Deleite Confinado. https://drive. google.com/file/d/1z2NDI3eAKfPm6R7sT2P6bxnjnCTDor41/ view?usp=sharing

» López, L. (2018). "Metodología aprendizaje basado en proyectos (ABP)". Didactia. Disponible en https://didactia.grupomasterd. es/blog/numero-12/metodologia-aprendizaje-basado-en-proyectos-abp

» Marqués, P. (2013). "Nuevas metodologías docentes para mejorar la formación y los resultados académicos de los estudiantes". Padres y Maestros. (21)351, 16-21.

»Moreno, I. (2002). Musas y nuevas tecnologías. El relato hipermedia. Madrid, España. Paidós.

» (RTVE. 30-09-2016). https://www.rtve.es/alacarta/videos/dias-decine/spain-in-day/3739675/).

» Sanz, V. (2016) Videoclip El Lobo. https://www.youtube.com/wat$\mathrm{ch} ? \mathrm{v}=\mathrm{A} 5 \times 89 \mathrm{qcH} 39 \mathrm{U}$

» Sito. https://www.sito.org/ 